\title{
Redesain Gearbox Rotary Parkir Menggunakan Software Berbasis Elemen Hingga
}

\author{
Aang Ferianto dan Alief Wikarta \\ Teknik Mesin, Fakultas Teknologi Industri, Institut Teknologi Sepuluh Nopember (ITS) \\ e-mail: wikarta@me.its.ac.id
}

\begin{abstract}
Abstrak-Rotary parkir adalah sebuah alat untuk memarkir mobil secara vertikal dengan sistem berputar. Salah satu bagian yang penting adalah sistem penggerak, yang berfungsi sebagai penggerak utama sistem agar palet bisa digerakkan. Tujuan dari penelitian ini untuk mendesain ulang gearbox sistem penggerak dari rotary parkir yang ada agar lebih optimal. Metode yang digunakan dalam penelitian ini adalah metode elemen hingga dengan menggunakan software. Optimasi space gearbox dilakukan dengan mengganti external gear existing dengan internal gear. Perubahan jenis gear mengakibatkan tumpuan berubah sehingga harus dilakukan desain ulang. Optimasi tebal roda gigi dilakukan agar lebih ringan. Hasil yang didapat dari penelitian ini adalah desain yang optimal, yaitu desain yang memiliki berat total roda gigi terendah dan jumlah tumpuan paling sedikit namun masih memenuhi syarat untuk dikatakan aman. Desain optimal yang didapat mengalami pengurangan berat total roda gigi sebesar $29.79 \%$ dan pengurangan jumlah tumpuan sebesar $75 \%$ dibandingkan dengan desain awal.
\end{abstract}

Kata Kunci-External gear, internal gear, gearbox, simulasi solidworks.

\section{PENDAHULUAN}

$\mathrm{P}$ ENAMBAHAN jumlah kepemilikan mobil dari tahun ke tahun terus bertambah. Tercatat rata-rata penambahann mobil sebesar \pm 1000 unit per tahun [1]. Masalah yang ditimbulkan dari semakin banyaknya mobil bukan hanya kemacetan lalu lintas, tapi juga semakin sempitnya lahan parkir. Salah satu kategori tempat parkir adalah tempat parkir non-konvensional (smart-parkir). Salah satu contoh smartparking adalah rotary parkir. Rotary parkir adalah sebuah alat untuk memarkir mobil secara vertikal dengan sistem berputar. Keunggulan dari alat ini adalah dengan megggunakan area yang sedikit (sekitar 3 mobil) dapat memarkir mobil banyak [2]. Jumlah mobil yang diparkir tergantung dari kapasitas. Secara garis besar beberapa komponen rotary parkir antara lain : (1) Structure, (2) Unit Palet, (3) Chain/Link, (4) Sistem Penggerak, seperti yang ditunjukkan pada Gambar 1(a). Sistem penggerak berfungsi sebagai penggerak utama sistem agar palet bisa digerakkan. Penelitian mengenai sistem penggerak rotary parking pernah dilakukan, seperti pada "Design and Analysis of Rotary Automated Car Parking Sistem" [3] oleh Prasad Pashte, Vaibhav Narkhede, Shubham Nade, Sanket More, dan Yogesh L. Maske dari RMD Sinhgad School of Engineering, Warje, Pune, India. Penelitian ini dilakukan untuk mendesain dan mengembangkan sistem parkir yang aman dimana sistem tersebut tidak akan merusak kendaraan dan sekitarnya. Pemodelan dan simulasi pada gearbox menggunakan software Solidworks. Penelitian mengenai hal ini juga pernah dilakukan, seperti pada "Modeling and Analysis Gear Box" [4] yang dilakukan oleh Ch. Ashok Kumar dan Puttapaka Nagaraju dari Anurag Engineering College, Telangana, India. Penelitian ini bertujuan untuk menganalisa beban-beban yang terjadi pada roda gigi pada gearbox melalui pemodelan dan simulasi menggunakan software Solidworks. Kondisi sistem penggerak pada rotary parkir yang ada, seperti yang ditunjukkan pada Gambar 1(b), terlihat bahwa gearbox membutuhkan banyak tempat untuk pemasangannya, serta terkesan rumit sehingga untuk proses parakitan menjadi sulit. Padahal sebaiknya gearbox yang digunakan tidak terlalu banyak memakan tempat. Pada penelitian ini, redesain gearbox dilakukan untuk menyederhanakan konstruksi dari sistem penggerak tersebut agar tidak terlalu memakan tempat sehingga proses perakitan maupun perawatan jadi lebih mudah. Ukuran roda gigi pada gearbox juga akan dioptimasi untuk mendapatkan ukuran tebal yang optimal guna mengurangi material yang digunakan sehingga menjadi lebih ringan. Sehingga dilakukan penelitian untuk mendesain ulang gearbox rotary parkir agar lebih optimal.

\section{DASAR TEORI}

\section{A. Roda Gigi}

Berdasarkan Gambar 2, roda gigi menerima 3 jenis beban yaitu beban tangensial, radial, dan normal. Persamaan untuk menghitung beban-beban tersebut ditunjukkan oleh persamaan 1,2 , dan 3 .

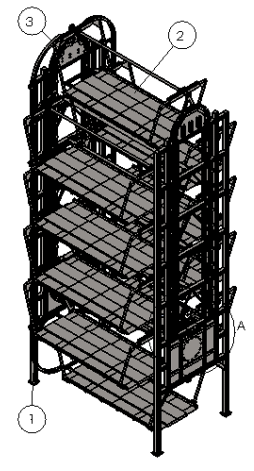

(a)

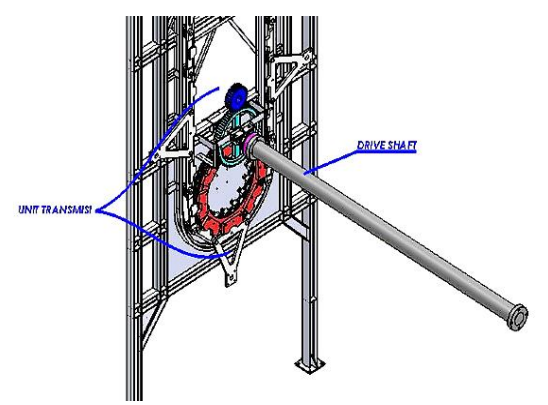

(b)
Gambar 1. Rotary Automated Car Parking (a) Unit sistem penggerak (b). [2]

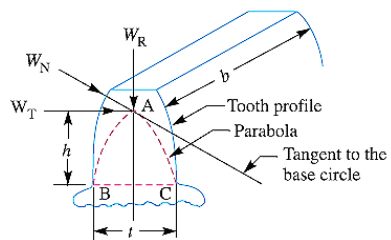

Gambar 2. Free-body diagram gigi. [5]

$$
\begin{aligned}
& W_{T}=\frac{P}{v} \times C_{s} \\
& W_{N}=\frac{W_{T}}{\operatorname{Cos} \theta} \\
& W_{R}=W_{N} \cdot \operatorname{Sin} \theta
\end{aligned}
$$

Dimana :

$$
\begin{array}{ll}
\mathrm{W}_{\mathrm{T}} & =\text { Beban tangensial, } \mathrm{N} \\
\mathrm{P} & =\text { Power }, \mathrm{W} \\
\mathrm{v} & =\text { Pitch line velocity, } \mathrm{m} / \mathrm{s}=\pi . \mathrm{d} . \mathrm{N} / 60
\end{array}
$$




$\begin{array}{ll}\mathrm{d} & =\text { Pitch Diameter }, \mathrm{m} \\ \mathrm{N} & =\text { Gear rotation }, \mathrm{rpm} \\ \mathrm{C}_{\mathrm{s}} & =\text { Service Factor } \\ \mathrm{W}_{\mathrm{N}} & =\text { Beban normal, } \mathrm{N} \\ \mathrm{W}_{\mathrm{R}} & =\text { Beban Radial, } \mathrm{N} \\ \theta & =\text { Pressure angle, }{ }^{\circ} \text { (derajat) }\end{array}$

Ada 2 jenis tegangan yang dialami roda gigi yaitu tegangan bending $\left(\sigma_{\mathrm{t}}\right)$ yang diakibatkan oleh $\mathrm{W}_{\mathrm{T}}$ dan tegangan kontak $\left(\sigma_{\mathrm{c}}\right)$ yang diakibatkan oleh $\mathrm{W}_{\mathrm{R}}$. Persamaan AGMA digunakan untuk menghitung kedua tegangan tersebut yang ditunjukkan oleh persamaan 4 dan 5 .

$$
\begin{aligned}
\sigma_{t} & =\frac{W_{T} K_{o} P K_{s} K_{m}}{K_{v} b J} \\
\sigma_{c} & =C_{p} \sqrt{\frac{W_{T} C_{o}}{C_{v}} \frac{C_{s}}{d b} \frac{C_{m} C_{f}}{I}}
\end{aligned}
$$

\section{B. Poros}

Beban yang diterima ada poros ada 2 yaitu beban bending dan torsi, maka harus diekivalenkan menggunakan persamaan 6. Setelah nilai torsi ekivalen diketahui, persamaan 7 digunakan untuk menghitung diameter poros. [5]

$$
T_{e}=\sqrt{\left(K_{m} \cdot M_{\max }\right)^{2}+\left(K_{t} \cdot T_{\max }\right)^{2}}
$$

$$
\text { Dimana : }
$$

$\mathrm{T}_{\mathrm{e}} \quad=$ Equivalent twisting moment, N.mm

$\mathrm{M}_{\max } \quad=$ Max. bending momen acting at the shaft, N.mm

$\mathrm{T}_{\max } \quad=$ Max. gear torsion, N.mm

$\mathrm{K}_{\mathrm{m}} \quad=$ Combined Shock and Fatigue Factor for Bending

$\mathrm{K}_{\mathrm{t}} \quad=$ Combined Shock and Fatigue Factor for torsion

$$
\begin{array}{cl}
\mathrm{T}_{\mathrm{e}}=\frac{\pi}{16} & \cdot \tau \cdot \mathrm{d}^{3} \\
\text { Dimana }: \tau & =\text { Allowable shear stress, MPa } \\
\mathrm{d} & =\text { Diameter poros, } \mathrm{mm}
\end{array}
$$

\section{METODOLOGI PENELITIAN}

\section{A. Kondisi Awal}

Untuk medesain ulang (redesain) gearbox sistem penggerak rotary parking, dibutuhkan spesifikasi kondisi awal (existing). Spesifikasi awal sistem penggerak rotary parking dapat dilihat pada Table 1. Gambar unit sistem penggerak dapat dilihat pada Gambar 3, sedangkan untuk gambar detail dan nama bagian unit gearbox dapat dilihat pada Gambar 4. Semua roda gigi pada Gambar 4 mempunyai modul 10 , tebal gigi $105 \mathrm{~mm}$, pressure angel $20^{\circ}$, dengan sistem $20^{\circ}$ Full-Depth Involute Gear. Rasio putaran yang dihasilkan sebesar 1:10 [2]. Dari Gambar 4 juga bisa diketahui bahwa semua roda gigi merupakan external gear.

\section{B. Desain Alternatif 1}

Pada dasarnya, dimensi roda gigi pada desain alternatif 1 sama dengan desain kondisi awal. Perbedaannya, pada desain alternatif 1 roda gigi 4 menggunakan internal gear agar tidak terlalu banyak memakan tempat. Penggantian jenis roda gigi 4 menyebabkan desain tumpuan harus dirubah, sehingga proses desain ulang harus dilakukan. Ada beberapa tumpuan yang digunakan yaitu : poros tumpuan 1 dan 2; 4 buah pillow block; dan support. Gambar unit sistem penggerak yang dengan desain alternatif 1 ditunjukkan oleh Gambar 5. Untuk gambar detail, dapat dilihat ada Gambar 6. Pada Gambar 6, ada beberapa bagian dalam yang masih belum bisa dilihat. Detail bagian dalam ditunjukkan pada Gambar 7 .

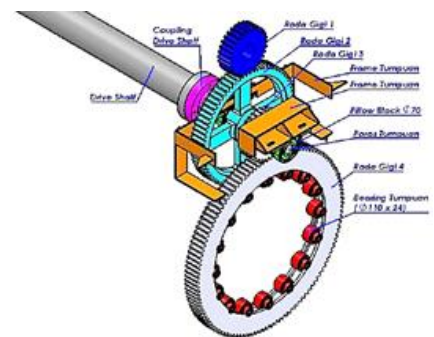

Gambar 3. Detail unit sistem penggerak. [2]

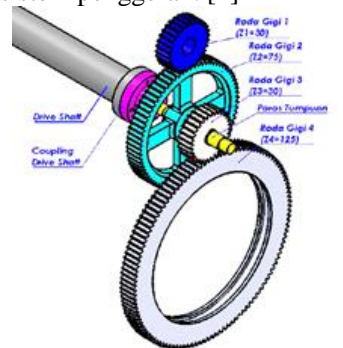

Gambar 4. Detail unit gearbox. [2]

Tabel 1. Spesifikasi awal rotary parkir. [2]

\begin{tabular}{cccc}
\hline \hline Jumlah Mobil & $\begin{array}{c}\text { Kecepatan } \\
\text { rotasi chain } \\
\text { (buah) }\end{array}$ & Waktu & $\begin{array}{c}\text { Daya motor } \\
\text { yang digunakan } \\
(\mathrm{mW})\end{array}$ \\
\hline 6 & 4 & 2 & 5 \\
10 & 4 & 3.5 & 7.5 \\
14 & 4 & 4.25 & 10 \\
16 & 4 & 5 & 10 \\
20 & 4 & 6.25 & 15 \\
\hline \hline
\end{tabular}

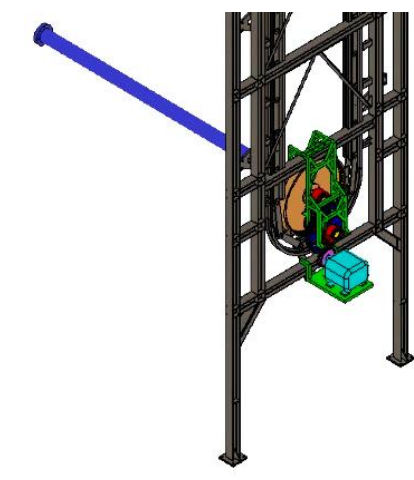

Gambar 5. Desain alternatif 1

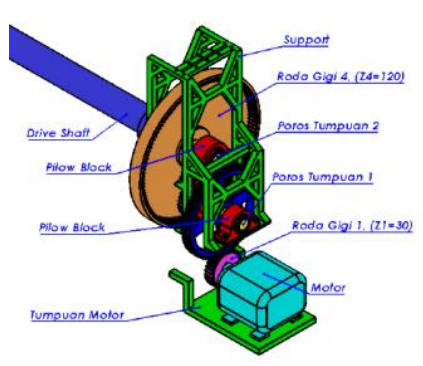

Gambar 6. Detail desain alternatif 1.

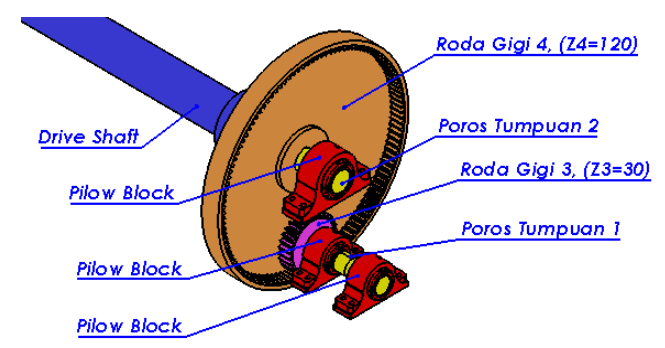

Gambar 7. Detail bagian dalam desain alternatif 1. 


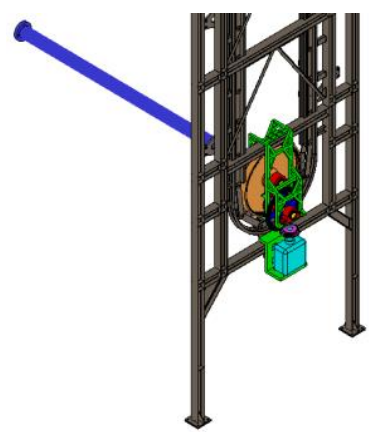

Gambar 8. Desain alternatif 2.

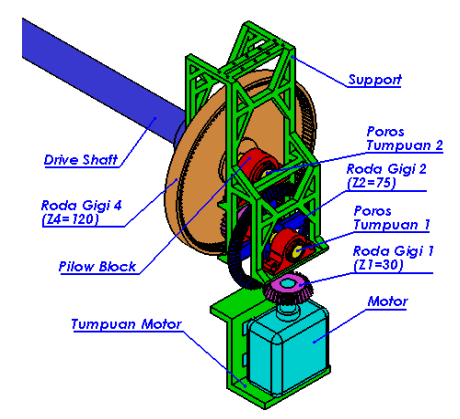

Gambar 9. Detail desain alternatif 2.

\section{Desain Alternatif 2}

Ada sedikit perbedaan antara desain alternatif 1 dengan desain alternatif 2 , yaitu pada roda gigi 1 dan roda gigi 2 . Pada desain alternatif 1 , keduanya menggunaan roda gigi lurus, sedangkan pada desain alternatif 2 keduanya menggunakan roda gigi kerucut yang parameter dasarnya sama dengan roda gigi lurus pada desain alternatif 1 . Gambar unit sistem penggerak yang menggunakan desain alternatif 2 ditunjukkan oleh Gambar 8. Untuk gambar detail, dapat dilihat ada Gambar 9. Pada Gambar 9, ada beberapa bagian dalam yang masih belum bisa dilihat. Detail bagian dalam ditunjukkan pada Gambar 7.

\section{Simulasi}

Pengujian yang hendak dilakukan dalam penelitian ini adalah simulasi pengujian pembebanan statis. Ada beberapa tahap, yaitu :

\section{1) Pemodelan}

Langkah pertama tahap pemodelan adalah mendefinisikan parameter-parameter yang dibutuhkan untuk menggambar/membuat suatu model, serta menentukan parameter apa yang akan divariasikan sehingga didapat beberapa variasi. Variasi yang digunakan pada peneltian ini adalah variasi tebal roda gigi $(\mathrm{t})$.

\section{2) Analisa Roda Gigi}

Tahap kedua dimulai dengan analisa dan perhitungan gayagaya yang terjadi pada roda gigi secara analitis. Langkah selanjutnya menentukan material yang mampu menahan beban tersebut berdasarkan referensi yang ada, kemudian simulasi. Model yang pertama disimulasikan adalah model dengan variasi pertama, yaitu roda gigi dengan modul 10 dan tebal $105 \mathrm{~mm}$. Meshing yang dilakukan adalah meshing standar karena kondisi yang akan diamati hanya pada surface model. Verifikasi meshing dilakukan dengan 2 cara. Pertama, dengan konvergent test yaitu kondisi dimana tidak ada perubahan yang besar pada tegangan maksimal yang terjadi seiring dengan berubahnya ukuran elemen meshing. Kedua, dengan mengamati posisi dari tegangan maksimal yang terjadi. Hasil simulasi dikatakan valid apabila telah memenuhi kedua verifikasi tersebut.

Kemudian setelah simulasi selesai dilakukan, dan syarat verifikasi simulasi sudah terpenuhi. Untuk validasi hasil simulasi yang berupa tegangan maksimal yang terjadi pada gigi dilakukan dengan membandingkannya dengan hasil perhitungan persamaan AGMA yang dilakukan secara analitis.

\section{3) Hasil Pengujian Roda Gigi}

Tahap ini terdiri dari peninjuan kembali hasil pengujian. Jika memenuhi persyaratan aman, maka pengujian diulang dengan variasi nilai tebal gigi berbeda yang lebih kecil. Hal ini terus dilakukan hingga variasi nilai tebal gigi tertentu tidak memenuhi persyaratan aman (gagal). Sehingga bisa diketahui pada nilai tebal gigi berapa roda gigi tersebut akan gagal (batas aman nilai tebal). Tebal gigi paling kecil yang masih memenuhi persyaratan aman bisa disebut tebal optimal roda gigi. Dari proses tahap ketiga ini akan diperoleh tebal optimal dari roda gigi.

\section{4) Analisa Tumpuan}

Penentuan dimensi dilakukan melalui perhitungan analitis. Dari nilai dimensi tersebut selanjutnya akan dibuat model 3D, ditentukan materialnya, kemudian disimulasikan. Jika tegangan maksimal yang diperoleh dari simulasi tidak melebihi tegangan ijin yang dibagi faktor keamanan $\left(\sigma_{\max } \leq\right.$ $\mathrm{S}_{\mathrm{y}} / \mathrm{FS}$ ), maka poros tumpuan dinyatakan aman. Untuk support, model 3D yang dimensi dan jenis materialnya sudah ditentukan sebelumnya akan disimulasi untuk mendapatkan tegangan maksimal. Dari proses tahap ke-empat ini akan diperoleh dimensi aman dari tumpuan.

\section{E. Analisa Hasil Simulasi dan Kesimpulan}

Hasil dari simulasi yang telah dilakukan kemudian dianalisa. Hasil tersebut hendaknya berupa tegangan maksimum yang terjadi baik pada tiap roda gigi maupun pada tiap tumpuan, batas aman nilai tebal roda gigi dan nilai dimensi aman tumpuan. Tegangan maksimum yang terjadi pada roda gigi akan dibandingkan dengan nilai tegangan ijin material tersebut. Roda gigi dikatakan aman jika tegangan yang terjadi kurang dari atau sama dengan tegangan ijin material. Untuk tumpuan dan support, desain dikatakan aman jika tegangan yang terjadi kurang dari atau sama dengan tegangan ijin material yang dibagi faktor keamanan.

\section{HASIL DAN ANALISA}

Setelah dilakukan analisa, perhitungan, dan simulasi terhadap desain awal, desain alternatif 1 , dan desain alternatif 2, maka langkah selanjutnya akan dilakukan pembahasan hasil simulasi.

\section{A. Kondisi Awal}

Untuk mempermudah, analisa akan dilakukan berdasarkan Gambar 4. Roda gigi 1 sebagai pinion. Material yang digunakan pada kondisi awal adalah Steel 450. Hasil perhitungan beban kondisi awal ditunjukkan pada Tabel 2. Hasil perhitungan nilai tegangan yang dilakukan secara analitis ditunjukkan pada Tabel 3 .

Tabel 2.

Beban kondisi awal.

\begin{tabular}{cccc}
\hline \hline $\begin{array}{c}\text { Roda } \\
\text { Gigi } \\
\text { ke- }\end{array}$ & $\begin{array}{c}\text { Beban } \\
\text { Tangensial } \\
\left(\mathrm{W}_{\mathrm{T}}\right)\end{array}$ & $\begin{array}{c}\text { Beban } \\
\text { Normal } \\
\left(\mathrm{W}_{\mathrm{N}}\right)\end{array}$ & $\begin{array}{c}\text { Beban } \\
\text { Radial } \\
\left(\mathrm{W}_{\mathrm{R}}\right)\end{array}$ \\
\hline 1 & 20.25 & 21.55 & $\mathrm{kN}$ \\
\hline 2 & 20.25 & 21.55 & 7.38 \\
3 & 50.63 & 53.88 & 18.43 \\
4 & 50.63 & 53.88 & 18.43 \\
\hline \hline
\end{tabular}

Nilai tegangan kondisi awal.

\begin{tabular}{ccccc}
\hline \hline $\begin{array}{c}\text { Roda } \\
\text { Gigi }\end{array}$ & \multicolumn{2}{c}{$\begin{array}{c}\text { Tegangan yang Terjadi } \\
(\mathrm{MPa})\end{array}$} & \multicolumn{2}{c}{$\begin{array}{c}\text { Tegangan Ijin } \\
(\mathrm{MPa})\end{array}$} \\
$\mathrm{Ke}-$ & $\sigma_{\mathrm{t}}$ & $\sigma_{\mathrm{c}}$ & $\mathrm{S}_{\mathrm{ad}}$ & $\mathrm{S}_{\mathrm{ac}}$ \\
\hline 1 & 145.789 & 42.86 & 403.481 & 468.85 \\
2 & 145.058 & 27.039 & 403.481 & 468.85 \\
3 & 364.473 & 67.768 & 403.481 & 468.85 \\
4 & 360.684 & 33.707 & 403.481 & 468.85 \\
\hline \hline
\end{tabular}

Dari Tabel 3, diketahui bahwa tegangan bending yang terjadi masih jauh di bawah tegangan ijin karena bending. Hal 
ini menunjukkan bahwa tebal roda gigi masih bisa dioptimasi. Optimasi dilakukan untuk mendapatkan dimensi tebal roda gigi yang lebih kecil namun masih aman (tebal optimal). Dari Tabel 4.2 juga bisa dilihat bahwa tegangan kontak yang terjadi jauh lebih kecil dibanding tegangan bending yang terjadi. Maka dapat diasumsikan bahwa jika roda gigi aman karena tegangan bending, maka ia juga aman karena tegangan kontak. Jadi untuk selanjutnya analisa keamanan tebal roda gigi akan dilakukan berrdasarkan tegangan bending yang terjadi.

\section{B. Desain Alternatif 1}

Untuk mempermudah, pembahasan akan dilakukan berdasarkan Gambar 6 dan 7, dimana roda gigi 1 sebagai pinion. Material yang roda gigi desain alternatif 1 adalah DIN 35S20 (Baja ST60) dengan Ultimate Tensile Stress $600 \mathrm{MPa}$ dan Yield Stress $380 \mathrm{MPa}$.

Setelah simulasi memenuhi syarat verifikasi, perlu dilakukan validasi. Grafik perbandingan nilai hasil simulasi dengan analitis ditunjukkan pada Gambar 10. Pada Gambar 10, dapat dilihat grafik nilai tegangan hasil simulasi memiliki trendline yang sama dengan hasil analitis. Nilai error terbesar yaitu $2.08 \%$, pada roda gigi 1 dan 3. Nilai error terjadi karena dua metode pendekatan yang digunakan berbeda. Dengan demikian dapat dikatakan bahwa hasil simulasi dapat mewakili hasil analitis.

Langkah selanjutnya adalah optimasi ketebalan roda gigi. Optimasi dilakukan menggunakan Design Study pada Solidworks. Variasi yang digunakan adalah ketebalan roda gigi (t). Hasil Design Study berupa grafik ditunjukkan pada Gambar 11. Pada Gambar 10, nilai tegangan ijin digambarkan dengan garis sejajar sumbu $\mathrm{x}$. Tebal roda gigi dikatakan optimal apabila memiliki tebal terkecil namun tegangan yang terjadi masih di bawah tegangan ijin. Karena roda gigi beroperasi secara berpasangan, maka tebal roda gigi dikatakan optimal ketika semua pasangan roda gigi, yaitu roda gigi 1,2, 3, dan 4, memiliki tegangan maksimal yang masih di bawah tegangan ijin. Dari grafik pada Gambar 11, dapat diketahui tebal optimal roda gigi sebesar $75 \mathrm{~mm}$, karena masih di bawah garis tegangan ijin.

\section{Desain Alternatif 2}

Untuk mempermudah, pembahasan akan dilakukan berdasarkan Gambar 9 dan 7, dimana roda gigi 1 sebagai pinion. Material yang digunakan roda gigi desain alternatif 2 sama dengan desain alternatif 1 . Proses yang dilakukan juga sama dengan desain alternatif 1 . Grafik perbandingan nilai hasil simulasi dengan analitis ditunjukkan pada Gambar 12. Pada Gambar 12, dapat dilihat grafik nilai tegangan hasil simulasi memiliki trendline yang sama dengan hasil analitis. Nilai error terbesar yaitu $2.08 \%$, pada roda gigi 3. Nilai error terjadi karena dua metode pendekatan yang digunakan berbeda. Dengan demikian dapat dikatakan bahwa hasil simulasi dapat mewakili hasil analitis. Hasil Design Study berupa grafik ditunjukkan pada Gambar 13. Pada Gambar 13, nilai tegangan ijin digambarkan dengan garis sejajar sumbu $\mathrm{x}$.

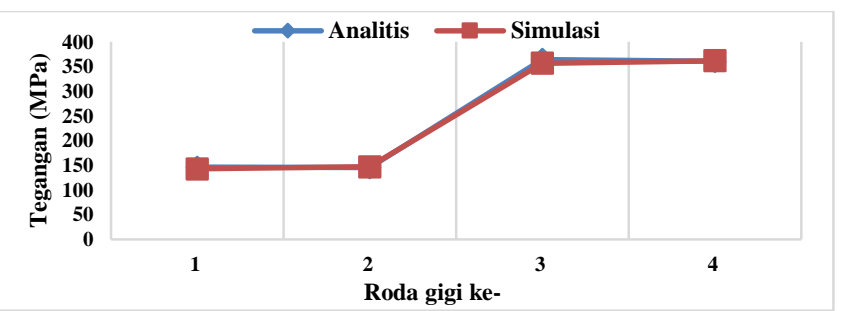

Gambar 10. Nilai tegangan roda gigi desain alternatif 1.

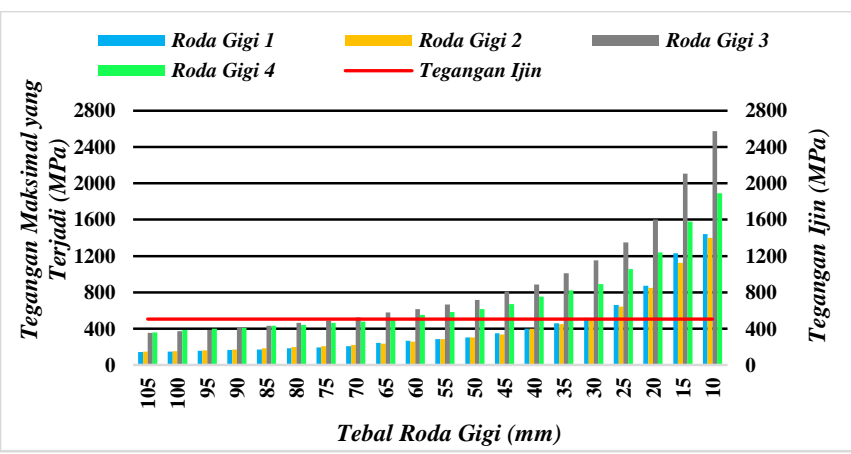

Gambar 11. Hubungan tegangan maksimal dengan tebal roda gigi desain alternatif 1 .

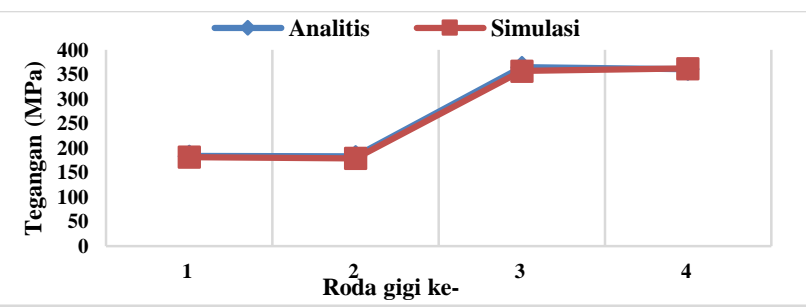

Gambar 12. Nilai tegangan roda gigi desain alternatif 2 .

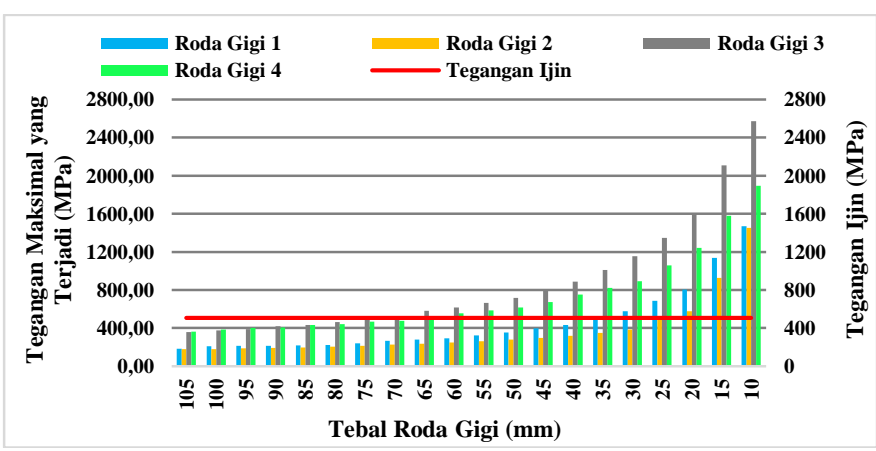

Gambar 13. Hubungan tegangan maksimal dengan tebal roda gigi desain alternatif 2 .

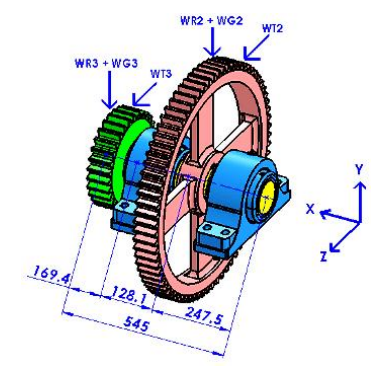

Gambar 14. Free-body diagram poros tumpuan 1.

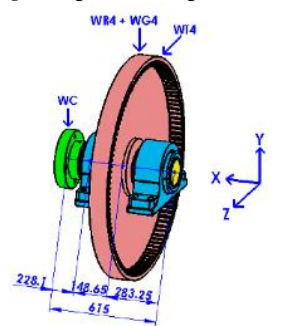

Gambar 15. Free-body diagram poros tumpuan 2. 


\section{Poros Tumpuan}

Setelah tebal roda gigi optimal sudah diketahui langkah selanjutnya adalah mendesain poros tumpuan. Tujuan dari proses desain ini adalah untuk mendapatkan dimensi aman dari poros. Material yang akan digunakan untuk poros sama dengan roda gigi.

\section{1) Poros Tumpuan 1}

Untuk mempermudah, analisa akan dilakukan berdasarkan Gambar 14. Kemudian dengan bantuan software MDSolids diketahui diagram gaya geser dan momen bending pada bidang XY dan XZ. Pada bidang XY didapat momen bending maksimum sebesar $3184.38 \mathrm{kN} . \mathrm{mm}$, dan pada bidang $\mathrm{XZ}$ didapat 8575.88 kN.mm. Sehingga dapat dihitung momen bending total dan didapat sebesar $9148.01 \mathrm{kN} . \mathrm{mm}$. Torsi maksimum terjadi pada roda gigi 2 yaitu sebesar 7568.44 kN.mm. Sehingga dapat dihitung torsi ekivalen dan didapat sebesar 23745.93 kN.mm. Dari hasil perhitungan analitis didapat diameter poros sebesar $108.4 \mathrm{~mm}$ yang dibulatkan menjadi $110 \mathrm{~mm}$.

Langkah selanjutnya adalah simulasi sebagai validasi. Angka keamanan yang digunakan sebesar 4, sehingga tegangan ijin sebesar $95 \mathrm{MPa}$. Hasil simulasi ditunjukkan pada Gambar 16. Dari Gambar 16, dapat diketahui bahwa tegangan yang terjadi sebesar 93.09 $\mathrm{MPa}$, yang masih lebih kecil dibanding tegangan ijin yaitu $95 \mathrm{MPa}$. Jadi dapat dikatakan bahwa poros tumpuan dengan dimensi $110 \mathrm{~mm}$ aman dengan simulasi yang mempunyai error sebesar $2.01 \%$.

\section{2) Poros Tumpuan 2}

Untuk mempermudah, analisa akan dilakukan berdasarkan Gambar 15. Proses analisa yang dilakukan sama dengan proses analisa pada poros tumpuan 1. Sehingga didapat momen bending maksimum pada bidang XY 1787.8 kN.mm, dan pada bidang XZ didapat 3768.65 kN.mm. Momen bending total didapat sebesar $4171.21 \mathrm{kN} . \mathrm{mm}$. Torsi maksimum terjadi pada roda gigi 4 yaitu sebesar 30438.29 kN.mm. Torsi ekivalen yang didapat sebesar Sehingga dapat dihitung torsi ekivalen dan didapat sebesar 61445.52 kN.mm. Kemudian didapat diameter poros sebesar $148.82 \mathrm{~mm}$ yang dibulatkan menjadi $150 \mathrm{~mm}$.

Hasil simulasi yang ditunjukkan oleh Gambar 17, menunjukkan tegangan yang terjadi sebesar 99.09 MPa. Meskipun tegangan hasil simulasi lebih besar dibanding tegangan ijin yaitu $95 \mathrm{MPa}$, poros tumpuan dengan dimensi $150 \mathrm{~mm}$ bisa dikatakan aman dengan catatan bahwa error simulasi sebesar $4.3 \%$

\section{E. Bearing}

Bearing yang akan digunakan adalah bearing jenis pillow block. Berdasarkan diameter poros tumpuan yang sudah didapat, maka diameter pillow block untuk poros tumpuan 1 ditentukan sebesar $110 \mathrm{~mm}$. Sedangkan untuk poros tumpuan 2 sebesar $150 \mathrm{~mm}$. Setelah dilakukan pengecekan pada katalog pillow block, untuk pillow block dengan diameter poros $110 \mathrm{~mm}$ dan $150 \mathrm{~mm}$ tersedia. Pillow block yang digunakan adalah pillow block merk Baldor tipe E, dengan nomor 023633 untuk poros tumpuan 1, dan nomor 023638 untuk poros tumpuan 2.

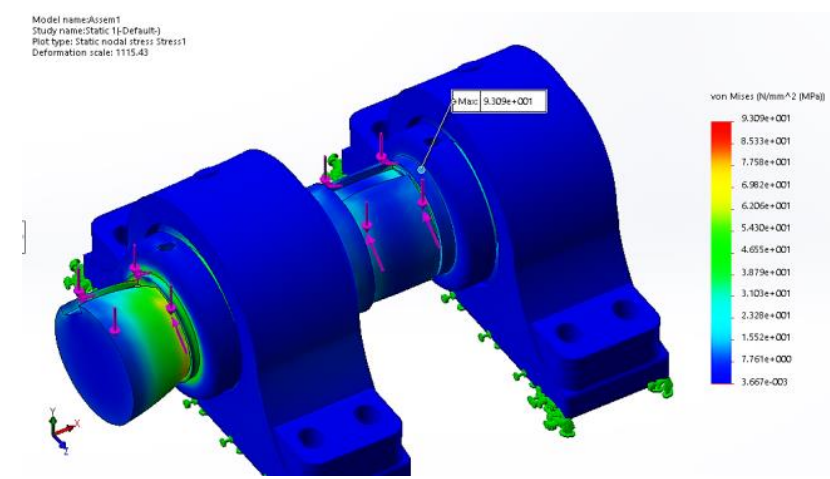

Gambar 16. Hasil simulasi poros tumpuan 1.

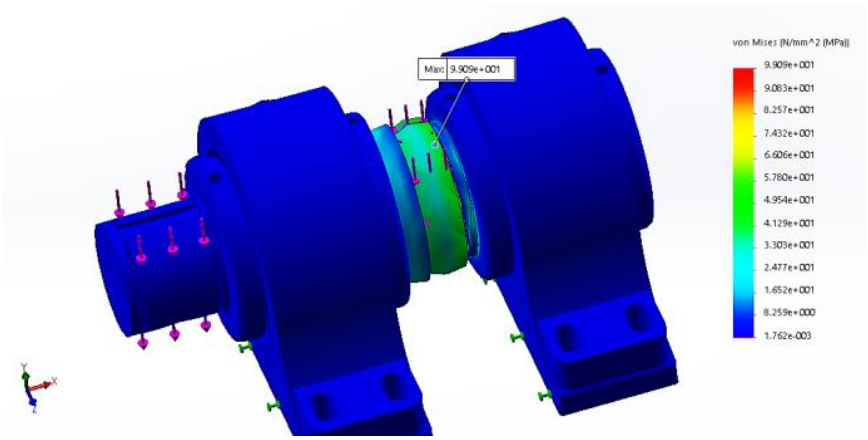

Gambar 17. Hasil simulasi poros tumpuan 2.
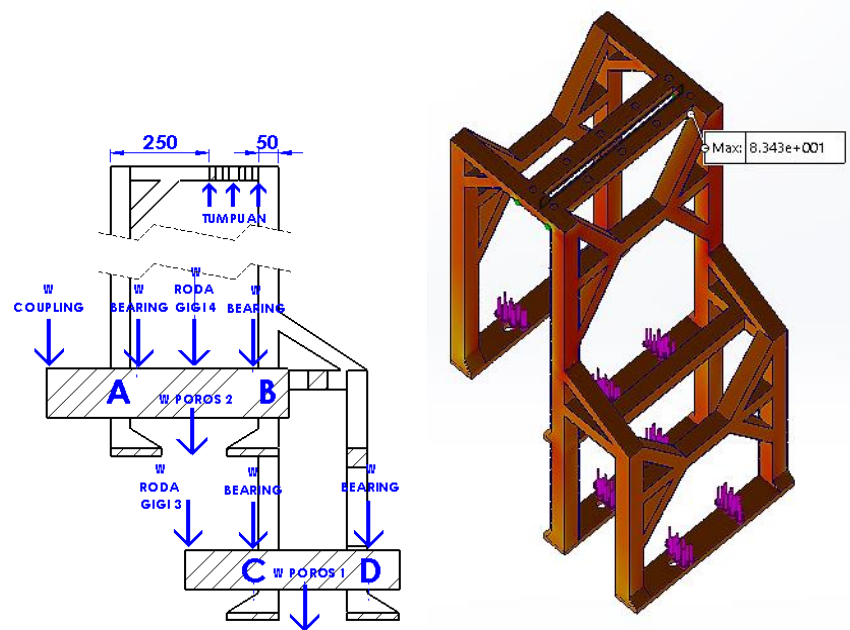

Gambar 18. Free-body diagram support. Gambar 19. Hasil simulasi support.

\section{F. Support}

Langkah awal adalah analisa beban-beban yang bekerja. Gambar free-body diagram support ditunjukkan pada Gambar 17. Dengan perhitungan analitis didapat beban pada titik $A$ dan B masing-masing sebesar $3551.907 \mathrm{~N}$, dan titik C dan D masing-masing sebesar $1180.143 \mathrm{~N}$. Beban ini kemudian dijadikan input untuk simulasi.

Material yang digunakan untuk support ini adalah profil kotak berlubang DIN S355 berukuran 50x50x4 yang memiliki ultimate tensile strength $520 \mathrm{MPa}$. Hasil simulasi yang ditunjukkan Gambar 18 menunjukkan nilai tegangan sebesar 83.43 MPa. Angka keamanan yang digunakan sebesar 4 sehingga tegangan ijin menjadi $130 \mathrm{MPa}$. Jadi, bisa dikatakan bahwa support aman. 


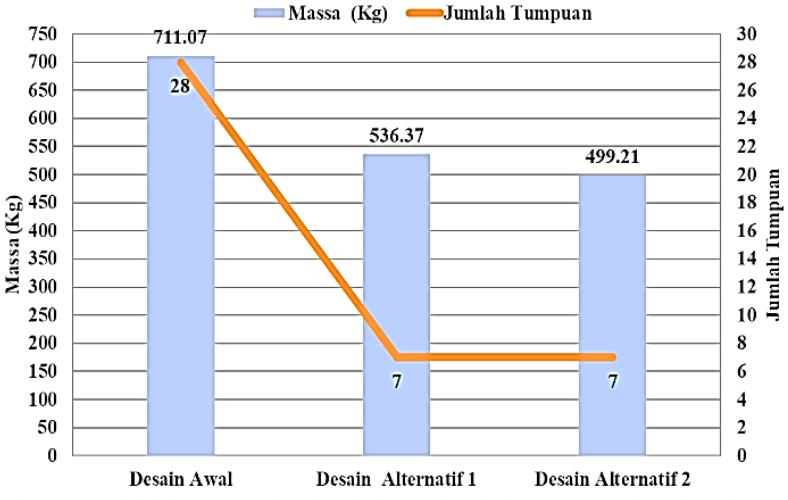

Gambar 20. Nilai berat total roda gigi dan jumlah tumpuan tiap desain.

\section{G. Perbandingan Desain Awal, Alternatif 1, dan Alternatif 2}

Langkah terakhir adalah membandingkan ketiganya untuk mendapatkan desain yang optimal dan sederhana. Desain yang optimal adalah desain yang memiliki berat total roda gigi terendah dan jumlah tumpuan paling sedikit namun masih memenuhi pesayaratan aman. Gambar 19 menunjukkan grafik Nilai berat total roda gigi dan jumlah tumpuan tiap desain. Dari grafik tersebut diketahui bahwa desain optimal adalah desain alternatif 2 .

\section{KESIMPULAN}

Dari hasil penelitian yang telah dilakukan dapat diambil kesimpulan sebagai berikut:

1. Tedapat 2 alternatif desain, yaitu :

a. Pada desain alternatif 1 , roda gigi 1,2 , dan 3 menggunakan spur gear, roda gigi 4 menggunakan internal gear agar tidak terlalu banyak memakan tempat. Penggantian jenis roda gigi 4 menyebabkan desain tumpuan harus dirubah, sehingga proses desain ulang harus dilakukan. Ada beberapa tumpuan yang digunakan yaitu : poros tumpuan 1 dan 2; 4 buah pillow block; dan support.

b. Perbedaan antara desain alternatif 1 dengan 2 adalah pada roda gigi 1 dan 2 . Roda gigi 1 dan 2 pada desain alternatif 2 menggunakan bevel gear dengan parameter yang sama dengan spur gear pada dsain alternatif 1.Tumpuan yang digunakan pada desain alternatif 2 juga sama dengan desain alternatif 1, yaitu : poros tumpuan 1 dan 2; 4 buah pillow block; dan support.

2. Berdasarkan hasil optimasi tebal roda gigi dari desain alternatif yang menggunakan material DIN S35S20 dengan tegangan ijin 505.41 MPa, didapatkan :

a. Tebal optimal roda gigi untuk desain alternatif 1 adalah $75 \mathrm{~mm}$ dengan tegangan maksimal yang terjadi adalah $489.13 \mathrm{MPa}$.

b. Tebal optimal roda gigi untuk desain alternatif 2 adalah $75 \mathrm{~mm}$ dengan tegangan maksimal yang terjadi adalah $489.13 \mathrm{MPa}$.

3. Berdasarkan perhitungan dan analisa tumpuan yang menggunakan material DIN S35S20, didapatkan :

a. Dimensi aman poros tumpuan 1 adalah 110 mm.

b. Dimensi aman poros tumpuan 2 adalah 150 mm.

c. Bearing yang digunakan adala bearing jenis pillow block merk Baldor tipe E dengan nomor 023633 untuk poros tumpuan 1, dan nomor 023638 untuk poros tumpuan 2.

d. Support dinyatakan aman dengan menggunakan profil Square Hollow Section DIN S355 berukuran 50x50x4. Tegangan maksimal yang terjadi dari hasil simulasi adalah 83.43 MPa, yang masih tidak lebih besar dari tegangan ijin material yaitu $130 \mathrm{MPa}$.

4. Dari hasil perbandingan dari semua desain, desain alternatif 2 merupakan desain yang optimal karena memiliki total berat roda gigi terendah yaitu sebesar 499.21 Kg dan jumlah tumpuan paling sedikit yaitu sebanyak 7 buah tumpuan.

\section{DAFTAR PUSTAKA}

[1] Badan Pusat Statistik Indonesia.

[2] "Parkit-kita.co.id."

[3] M. Y. L. M. Mr. Prasad Pashte, Mr. Vaibhav Narkhede, Mr Shubham Nade, Mr. Sanket More, "Design and Analysis of Rotary Automated Car Parking System," Int. J. Sci. Res. Dev., vol. 4, 2016.

[4] P. N. Ch. Ashok Kumar, "Modeling and Analysis Gear Box," Int J. Mag. Eng. Technol. Manag. Res., 2014

[5] J. K. G. Khurmi R. S., Machine Design (SI Units), Eurasia Publishing House (PVT.) LTD. New Delhi, 2005 